\title{
Clinical Commentary Survival from breast cancer in England and Wales up to 2001
}

\author{
A Leary' and IE Smith ${ }^{*, 1}$ \\ 'Breast Unit, Royal Marsden Hospital, NHS Foundation Trust, Fulham Road, London SW3 6JJ, London, UK
}

British Journal of Cancer (2008) 99, S56-S58. doi:I0.1038/sj.bjc.6604588 www.bjcancer.com

Published online 23 September 2008

(c) 2008 Cancer Research UK

Over the last 20 years, breast cancer has been something of a success story in the United Kingdom, with a $20 \%$ decrease in mortality despite a steadily increasing incidence. This is welcome news, but the underlying explanation is the topic of much debate. The widespread use of adjuvant medical therapies, the introduction of a national mammographic screening programme, and increased breast awareness all have their advocates. It is likely that all these factors are involved to a varying extent.

\section{THE UNCERTAIN ROLE OF SCREENING}

The NHS breast cancer screening programme was introduced in 1988 after mortality from breast cancer had already begun to decrease and was based on the results from eight randomized trials showing that screening reduced mortality by $20-30 \%$ especially for women between 50 and 69 years of age. Since then, the methodology of these trials and the magnitude of survival benefit have been the subject of continuous debate (Olsen and Gotzsche, 2001; Baum, 2004). The absolute survival benefit from screening is difficult to quantify in the setting of concomitant advances in the management of breast cancer. Some critics argue that the harms of screening mammography, for example, false positives with resulting unnecessary procedures and increased anxiety, may actually outweigh the benefits (Gotzsche, 2004). What is certainly clear is that screening has led to a dramatic increase in the incidence of ductal carcinoma in situ (DCIS). DCIS is a noninvasive form of breast cancer, usually detected as asymptomatic microcalcifications on mammography, which may or may not progress to invasive cancer. Before the NHS screening programme, DCIS had been a rare diagnosis, but now it accounts for approximately $20 \%$ of screen-diagnosed breast cancers (Moss et al, 1995). When appropriately treated, this non-invasive cancer has an excellent prognosis (10-year RR of death from breast cancer, 2\%; Ernster et al, 2000) and therefore has clearly contributed to the rising incidence of breast cancer while improving survival rates, but the impact on mortality of this dramatic increase in diagnosis remains uncertain. Reviews of autopsy series have revealed that DCIS is an incidental finding in 9\% of women dying of non-breast cancer-related causes (Welch and Black, 1997), suggesting that screen-detected DCIS may lead to overdiagnosis in some women. Likewise, retrospective studies have demonstrated that only $15-50 \%$ of untreated DCIS will progress to

*Correspondence: Professor IE Smith; E-mail: lan.smith@rmh.nhs.uk invasive disease (Erbas et al, 2006). The problem lies in identifying which ones will.

\section{BREAST AWARENESS}

Despite the high media profile for breast self-examination (BSE), an approach of systematic BSE has not been shown to improve survival and may actually cause anxiety and unnecessary biopsies (Kosters and Gotzsche, 2003). Breast awareness, however, is still promoted and involves encouraging women to recognise and report without delay any unusual breast changes (McCready et al, 2005). Improved public education about breast cancer combined with increased screening has led to a stage shift, with more women presenting with early disease.

\section{ADVANCES IN THE TREATMENT OF EARLY BREAST CANCER}

\section{Loco-regional treatment}

Surgery has always been central to the management of early breast cancer. Over the last few decades, however, it has become clear that access to surgical specialists is an important predictor of long-term outcome. Women with early breast cancer treated by specialist surgeons have lower local recurrence rates and an improved survival compared with those treated by non-specialists (Kingsmore et al, 2004). This benefit is in part attributable to higher rates of adequate local treatment of the breast and/or axilla. Increased access to specialist surgeons and the establishment of national guidelines for the surgical management of breast cancer (Quality assurance guidelines for surgeons in breast cancer screening, in Publication No. 20, N. BSP, Editor, 1992) have therefore contributed to survival improvements. Similarly, standardisation of pathology reporting and the use of specialized breast pathologists have been important factors in improving the quality of care delivered to women with breast cancer (Program, UNS, Pathology Reporting in Breast Cancer Screening, in 2nd edition, NPN 3, Editor, 1997: Sheffield UK). Finally, radiotherapy after breast-conserving surgery and after mastectomy in selected high-risk patients has been shown to improve not only loco-regional control, but also long-term survival (5\% reduction in 15-year breast cancer mortality) (Clarke et al, 2005). 


\section{Systemic treatment}

The last two decades have seen tremendous advances in the adjuvant treatment of early breast cancer. In 1985, the Nolvadex Adjuvant Trial Organisation study was the first randomised trial to show an overall survival advantage in patients receiving adjuvant treatment with the selective oestrogen receptor modulator, tamoxifen (NATO, 1985). Since then, a series of reviews have confirmed that 5 years of post-operative tamoxifen for pre- and post-menopausal women with $\mathrm{ER}+$ breast cancer reduces mortality by over $25 \%$ at up to 15 years of follow-up (EBCTCG, 1998a; EBCTCG, 2005).

Adjuvant chemotherapy trial data also began to emerge in the early 1980s, again suggesting a survival benefit particularly for young women (EBCTCG, 1988). Subsequent overview results confirmed a proportional mortality reduction of 27 and $11 \%$ among women below and above the age of 50, respectively, regardless of nodal status (EBCTCG, 1998b). Efforts have been made to determine the optimal cytotoxic regimen. The standard post-operative treatment in most early trials was CMF polychemotherapy (cyclophosphamide, methotrexate, and 5-fluorouracil), but recent evidence suggests that there is a small but highly significant further survival benefit with anthracycline-based regimens $(\mathrm{RR}=0.89 ; 2 P<0.00001)$ (EBCTCG, 2005), and these have become widely accepted as standard adjuvant chemotherapy.

The most recent overview suggests that breast cancer mortality may actually be halved by a combination of endocrine therapy and chemotherapy after surgery in women with hormone receptorpositive disease (EBCTCG, 2005). As these account for more than two-thirds of newly diagnosed breast cancer patients, it is likely that the increasing use of adjuvant therapy has had an important function in breast cancer survival improvement.

\section{ADVANCES IN THE TREATMENT OF METASTATIC BREAST CANCER}

A number of new cytotoxic, endocrine and targeted agents have been licensed for breast cancer over the last 15 years and have greatly increased treatment options for advanced disease (Smith, 2002). Although the impact on overall survival trends is likely to be modest, the incorporation of these new therapies into clinical practice has been shown to significantly prolong survival from metastatic breast cancer (OS from metastatic breast cancer: 438 days vs 667 days for women treated in 1991-1992 vs 1999-2001; Chia et al, 2007). By increasing the number of effective anti-cancer agents, and improving palliative strategies by offering radiotherapy for symptomatic bone and brain lesions, or surgical treatment of spinal and brain metastases, tremendous gains have been achieved in improving both the quality of life and survival of women with advanced breast cancer.

\section{THE DEPRIVATION GAP}

Quinn et al (2008) draw attention to the observation that although the incidence of breast cancer has risen more rapidly among affluent women, the deprivation gap (difference in survival from breast cancer for women from affluent $v s$ deprived background) has not changed. This may in part be due to the fact that women from a higher socioeconomic background are more likely to undergo mammography and therefore be diagnosed with a small screen-detected breast cancer (Taylor and Cheng, 2003). However, as Quinn et al (2008) point out, if screening were the sole reason for the increased incidence, this should have led to a stage shift in the affluent group and a widening in the deprivation gap. Women of higher socioeconomic status are also at increased risk of developing invasive breast cancer due to differing reproductive behaviours of aetiological significance, for example, late age at first birth, low parity, and low breastfeeding rates (Kelsey et al, 1981). The incidence trend may therefore also reflect changes in reproductive habits and possibly in the use of hormone replacement therapy among affluent women.

\section{OPTIMISM FOR THE FUTURE}

On the premise that adjuvant medical therapies are a major factor in survival improvement, it is likely that this trend will continue with the emergence of new and more effective therapies.

Several trials have shown that adjuvant aromatase inhibitors achieve superior disease-free survival to tamoxifen in postmenopausal women, and it seems likely that this will translate into a further small survival improvement (Lin and Winer, 2008). Specifically, the MA-17 trial has demonstrated a significant improvement in disease-free survival for letrozole $v s$ placebo after 5 years of tamoxifen and a significant overall survival benefit in women with node-positive disease ( $\mathrm{HR}=0.61, P=0.04)$ (Goss et al, 2005), raising the concept of long-term maintenance endocrine therapy for 10 years or more in selected patients.

Adjuvant trastuzumab (Herceptin) has recently shown an impressive $50 \%$ reduction in the risk of early recurrence and a $30 \%$ reduction in mortality relative to placebo in women with HER2-positive breast cancer (Romond et al, 2005; Dinh et al, 2007). Although this involves only $15 \%$ of breast cancer patients, these represent a high-risk group, and the proof of principle gives optimism for further targeted therapies now in development.

Perhaps as important as the development of novel therapies is the development of tools to identify women with good prognosis who could benefit from more conservative treatment. Some of the new techniques include sentinel node biopsy to identify patients who may be spared axillary dissection and gene expression profiles to identify women at low risk of recurrence who may be spared adjuvant chemotherapy.

Finally, the changes in cancer treatment provision such as the increasing use of multidisciplinary teams, one-stop triple assessment clinics for symptomatic breast complaints and breast cancer nurse specialists will undoubtedly continue to optimise the quality of care offered to women with breast cancer.

\section{CONCLUSION}

Improvements in breast cancer diagnosis and treatment in the UK have had an important impact on survival, and it is reasonable to expect that the outlook will continue to improve over the next decade. Governmental guidelines implemented in the late 1990s designed to reduce delays and improve multidisciplinary organisation and the continuing development of more effective medical therapies are both making important contributions. The political challenge is to ensure equal access to best care for women from deprived backgrounds. The medical challenge is to select through molecular profiling which patients are most likely to benefit from the ever-expanding medical treatment options and which can be spared unnecessary toxicities. The good news is likely to continue.

\section{REFERENCES}

Baum M (2004) Commentary: false premises, false promises and false positives - the case against mammographic screening for breast cancer. Int J Epidemiol 33: 66-67; discussion 69-73
Chia SK, Speers CH, D’yachkova Y, Kang A, Malfair-Taylor S, Barnett J, Coldman A, Gelmon KA, O’Reilly SE, Olivotto IA (2007) The impact of new chemotherapeutic and hormone agents on survival in a 
population-based cohort of women with metastatic breast cancer. Cancer 110: 973 - 979

Clarke M, Collins R, Darby S, Davies C, Elphinstone P, Evans E, Godwin J, Gray R, Hicks C, James S, MacKinnon E, McGale P, McHugh T, Peto R, Taylor C, Wang Y, Early Breast Cancer Trialists' Collaborative Group (EBCTCG) (2005) Effects of radiotherapy and of differences in the extent of surgery for early breast cancer on local recurrence and 15-year survival: an overview of the randomised trials. Lancet 366: 2087-2106

Dinh P, de Azambuja E, Piccart-Gebhart MJ (2007) Trastuzumab for early breast cancer: current status and future directions. Clin Adv Hematol Oncol 5: 707-717

Early Breast Cancer Trialists' Collaborative Group (EBCTCG) (1988) Effects of adjuvant tamoxifen and of cytotoxic therapy on mortality in early breast cancer. An overview of 61 randomized trials among 28896 women. N Engl J Med 319: 1681-1692

Early Breast Cancer Trialists' Collaborative Group (EBCTCG) (1998a) Tamoxifen for early breast cancer: an overview of the randomised trials Lancet 351: $1451-1467$

Early Breast Cancer Trialists' Collaborative Group (EBCTCG) (1998b) Polychemotherapy for early breast cancer: an overview of the randomised trials. Lancet 352: $930-942$

Early Breast Cancer Trialists' Collaborative Group (EBCTCG) (2005) Effects of chemotherapy and hormonal therapy for early breast cancer on recurrence and 15-year survival: an overview of the randomised trials Lancet 365: $1687-1717$

Erbas B, Provenzano E, Armes J, Gertig D (2006) The natural history of ductal carcinoma in situ of the breast: a review. Breast Cancer Res Treat 97: $135-144$

Ernster VL, Barclay J, Kerlikowske K, Wilkie H, Ballard-Barbash R (2000) Mortality among women with ductal carcinoma in situ of the breast in the population-based surveillance, epidemiology and end results program. Arch Intern Med 160: $953-958$

Goss PE, Ingle JN, Martino S, Robert NJ, Muss HB, Piccart MJ, Castiglione M, Tu D, Shepherd LE, Pritchard KI, Livingston RB, Davidson NE, Norton L, Perez EA, Abrams JS, Cameron DA, Palmer MJ, Pater JL (2005) Randomized trial of letrozole following tamoxifen as extended adjuvant therapy in receptor-positive breast cancer: updated findings from NCIC CTG MA.17. J Natl Cancer Inst 97: $1262-1271$
Gotzsche PC (2004) On the benefits and harms of screening for breast cancer. Int J Epidemiol 33: 56-64; discussion 69-73

Kelsey JL, Fischer DB, Holford TR, LiVoisi VA, Mostow ED, Goldenberg IS, White C (1981) Exogenous estrogens and other factors in the epidemiology of breast cancer. J Natl Cancer Inst 67: 327-333

Kingsmore D, Hole D, Gillis C (2004) Why does specialist treatment of breast cancer improve survival? The role of surgical management. Br J Cancer 90: 1920 - 1925

Kosters JP, Gotzsche PC (2003) Regular self-examination or clinical examination for early detection of breast cancer. Cochrane Database Syst Rev 2: CD003373

Lin NU, Winer EP (2008) Advances in adjuvant endocrine therapy for postmenopausal women. J Clin Oncol 26: 798-805

McCready T, Littlewood D, Jenkinson J (2005) Breast self-examination and breast awareness: a literature review. J Clin Nurs 14: 570-578

Moss SM, Michel M, Patnick J, Johns L, Blanks R, Chamberlain J (1995) Results from the NHS breast screening programme 1990-1993. J Med Screen 2: $186-190$

Nolvadex Adjuvant Trial Organisation (NATO) (1985) Controlled trial of tamoxifen as single adjuvant agent in management of early breast cancer. Analysis at six years by Nolvadex Adjuvant Trial Organisation. Lancet 1: $836-840$

Olsen O, Gotzsche PC (2001) Cochrane review on screening for breast cancer with mammography. Lancet 358: $1340-1342$

Quinn MJ, Cooper N, Rachet B, Mitry E, Coleman MP (2008) Survival from cancer of the breast in women in England and Wales up to 2001. Br J Cancer 99(Suppl 1): S53-S55

Romond EH, Perez EA, Bryant J, Suman VJ, Geyer Jr CE, Davidson NE, Tan-Chiu E, Martino S, Paik S, Kaufman PA, Swain SM, Pisansky TM, Fehrenbacher L, Kutteh LA, Vogel VG, Visscher DW, Yothers G, Jenkins RB, Brown AM, Dakhil SR, Mamounas EP, Lingle WL, Klein PM, Ingle JN, Wolmark N (2005) Trastuzumab plus adjuvant chemotherapy for operable HER2-positive breast cancer. $N$ Engl $J$ Med 353: $1673-1684$

Smith IE (2002) New drugs for breast cancer. Lancet 360: $790-792$

Taylor A, Cheng KK (2003) Social deprivation and breast cancer. J Public Health Med 25: 228-233

Welch HG, Black WC (1997) Using autopsy series to estimate the disease 'reservoir' for ductal carcinoma in situ of the breast: how much more breast cancer can we find? Ann Intern Med 127: 1023-1028 